\section{Dental examiners consistency in applying different oral health indices in permanent dentition for a population-based study.}

\section{Valeria Campos ${ }^{1} \&$ Luis Luengo. ${ }^{1}$}

Abstract: Different indices to identify dental diseases have been developed. For population-based studies, it is imperative to use simple and reliable indices, but most importantly, clinical examiners should reach an agreement, in order to increase inter-observer reliability and obtain reliable data. The objective of this study was to describe the calibration process of the Dental Aesthetic Index, Community Periodontal Index, Simplified Oral Hygiene Index and International Caries Detection and Assessment System ICDAS II by two academics from the Public Health Department of Dentistry. All calibrations started with the individual reading of the official documents of each index and, when possible, were followed by a lecture, in-vitro or ex-vivo training and concluded with an in-vivo training. A high inter-observer reliability was obtained between the two academics in all indices.

Keywords: Agreement; Calibration; ICDAS; Dental examination.

\section{INTRODUCTION}

The global burden of oral diseases is widely known, in which dental caries and periodontal diseases are considered the most important (Petersen, 2003). A poor oral health is associated with systemic diseases (Petersen, 2003; Manger et al., 2017; D'Aiuto et al., 2017). Also, it has been established that oral health is a determinant factor for quality of life (Petersen, 2003; Dietrich et al., 2017; Gil-Montoya et al., 2015). Although malocclusion is a dental deviation rather than a disease, an association with lower self-esteem and poorer quality of life has also been established (Petersen, 2003; Sun et al., 2017; Dimberg et al., 2014; Taibah \& Al-Hummayani, 2017; CartesVelásquez et al., 2010).

Throughout the years, different indices to identify these diseases have been developed. For periodontal diseases, the World Health Organization (WHO) recommends the use of the Community Periodontal Index (CPI), which identifies loss of attachment, gingival bleeding and periodontal pockets (World Health Organization, 2013). This index examines 1.1, 3.1 and all first and second permanent molars, to obtain the index; the sextant with the worst value is selected (World Health Organization, 2013). Another universally accepted index is the Simplified Oral Hygiene Index (OHI-S), a rapid method for assessing cleanliness in populations (Petersen, 2003; Greene \& Vermillion, 1964; Mashima et al., 2017; Suresan, 2017). The OHI-S comprises a simplified debris index (DI-S) and a simplified calculus index (Cl-S), these indices are based on numerical determinations representing the amount of debris or calculus found on the preselected tooth surfaces. The OHI-S is the total of

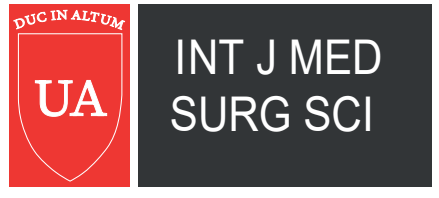

Affiliation: ${ }^{1}$ Universidad de Concepción School of Dentistry, Chile.

Corresponding: Dra . Valeria Campos Cannobbio. Roosevelt 1550, Concepción, Chile. Phone: +56987690058 . Email: valeriacamposcannobbio@gmail.com.

$\begin{array}{ll}\text { Receipt: } & 12 / 25 / 2018 \\ \text { Revised: } & 01 / 05 / 2019 \\ \text { Acceptance: } & 01 / 21 / 2019 \\ \text { Online: } & 01 / 25 / 2019\end{array}$

Conflict of interests: None.

Ethics approval: This study has been approved by the Commission of Research and Bioethics of the Universidad de Concepción School of Dentistry, Chile.

\section{Funding: None.}

Authors' contributions: All authors carried out the entire study.

Acknowledgements: None.

doi: $10.32457 /$ ijmss.2018.024 
the scores obtained in the DI-S and the Cl-S (Petersen, 2003; Greene \& Vermillion, 1964; Mashima et al., 2017; Suresan, 2017). For dentofacial anomalies, the Dental Aesthetic Index (DAI) has been widely used and accepted (Onyeaso \& Begole, 2007; Cardoso et al., 2011; WHO, 1997), as it has been a good predictor of future orthodontic treatment (Spencer et al., 1992) and an 88\% agreement between orthodontists' decisions and DAI scores has been reported (Jenny et al., 1993; Jenny \& Cons, 1996). This index evaluates 10 occlusal characteristics and the final scores are categorized in 4 levels of malocclusion severity (WHO, 1997). Although DMFT index has been widely used for caries detection, in 2005 and focused on an early detection, the International Caries Detection and Assessment System (ICDAS II) was established, which was designed to detect carious lesions ranging from an early clinically visible stage (Pitts, 2004). ICDAS II has been widely used and has been shown to be reliable in detecting dental caries (Ismail et al., 2007).

For population-based studies, it is imperative to use simple and reliable indices, but most importantly, clinical examiners should reach an agreement, in order to increase inter-observer reliability and obtain reliable data. In the context of a population-based study to identify oral health morbidities in Chilean Deaf population, a calibration was conducted for the DAI, CPI, OHI-S and ICDAS II indices by two pediatric dentists from the Public Health Department at the Dentistry Faculty of the Universidad de Concepción.

\section{MATERIALS AND METHODS}

This study has been approved by the Commission of Research and Bioethics of the Universidad de Concepción School of Dentistry, Chile. Patients recruitment was through convenience sampling, with a total of 10 patients. Informed and signed consent was obtained from patients or their tutors. All patients were over 12 years old (ranged 12-40), with permanent dentition, from different socioeconomic status. Edentulous patients were excluded. All patients received a financial incentive to pay for their transportation or other related expenses. The same patients participated in the pre calibration process of CPI, OHI-S and ICDAS II indices. For the DAI pre calibration process, dental study casts in plastic occluder were used. For the ex-vivo phase of
ICDAS II, permanent teeth were used. Equitable distribution between mandibular-maxillary, anterior-posterior, decayedsound, filled-nonfilled teeth.

Two examiners from the Public Health Department of the Dentistry Faculty of the Universidad de Concepción participated in the calibration process of all indices. All of them with a Master Degree in Pediatric Dentistry from the same generation and with private practice for at least 2 years as specialist.

All calibrations started with the individual reading of the official documents of each index and, when possible, were followed by a lecture, in-vitro or ex-vivo training and concluded with an in-vivo training.

All in-vivo examinations were developed according to the WHO Oral Health Surveys standards (World Health Organization, 2013).

DAl: After the reading of the DAI instructions from the WHO (WHO, 1997), a 2-hour group discussion was carried out by the examiners, questions were answered and with the help of illustrations, dental study casts from the archive of the Specialization Course in Orthodontics at the Faculty of Dentistry, Universidad de Concepción, Chile, and the utilization of the WHO/CPI/PSR probe (which is the probe for the DAI), a theoretical consensus was obtained between the examiners. Then, an in-vitro assessment was carried out, where each participant examined the study casts separately. The instruments used were those recommended for the index, the WHO/CPI/PSR probe and dental study casts, using a specially designed survey pro forma. Ten dental study casts in plastic occluder and without fractures were randomly selected from the Specialization Course in Orthodontics at the Faculty of Dentistry, Universidad de Concepción, the age of participants whose models were included in this study ranged from 12 to 15 years, with early permanent dentition and without previous orthodontic treatment. The assessment was carried out with artificial zenithal lighting in a beige room. Each assessment took 5 minutes per dental study cast, with a total of 40 minutes. After the collection of the data, DAl scores were calculated using the DAI regression equation, according to WHO (1997).

CPI and OHI-S: After the reading of the documents (Greene \& Vermillion, 1964; WHO, 1997), a lecture was 
given by a periodontist. After the lecture, questions were answered and with the help of images and illustrations, a theoretic consensus was obtained between the periodontist and the examiners. Later, an in-vivo training was carried out with 2 patients. Each participant examined the patients separately in a dental chair, artificial light, a mouth mirror $N^{\circ} 5$, WHO/CPI probe and using a specially designed survey pro forma. First, the OHI-S index was assessed, followed by the CPI. Each assessment took 5 minutes as a whole. Then, each patient was observed and discussed between the two examiners to obtain a clinical consensus of the indices. A week later, after reaching clinical consensus, a pre calibration process was carried out with 8 patients. Firstly, 4 patients were examined by each participant separately in a dental chair, artificial light, a mouth mirror $\mathrm{N}^{\circ} 5$, WHO/CPI probe and using a specially designed survey pro forma. First, the OHI-S index was assessed, followed by the CPI in four patients, then a 30 -minute recess took place followed by the examination of the last four patients. Each assessment took 5 minutes as a whole.

ICDAS: The training process was carried out following the ICDAS committee recommendations (Ismail et al., 2007) (https://www.iccms-web.com/). A Gold Standard was required, who was previously calibrated with the ICDAS GROUP (inter-examiner kappa 0.8). First, all the examiners read the Spanish version of the ICCMS ${ }^{\text {TM }}$ Guide for Practitioners and Educators (Guía ICCMS ${ }^{\mathrm{TM}}$ para clínicos $y$ educadores) and took the online course, for 4 hours. After the completion of the online course, each examiner and the GS individually, a training process was carried out using 169 images with a specially designed survey pro forma. Then, a lecture and a 2-hour group discussion was carried out by the GS using the same images and the WHO/CPI probe recommended for this index, questions were answered and with the help of the illustrations, a theoretic consensus was obtained between the GS and the examiners. After the theoretic consensus, an ex-vivo visual-tactile examination training using the $\mathrm{WHO} / \mathrm{CPI}$ probe, was carried out using extracted teeth, evaluating 1-2 surfaces each. 18 permanent teeth were randomly selected from the Department of Restorative Dentistry at the Faculty of Dentistry, Universidad de Concepción, Chile. Equitable distribution between mandibular-maxillary, anterior-posterior, decayed-sound, filled-nonfilled teeth. Each participant examined the teeth separately using a WHO/CPI probe and a specially designed survey pro forma with artificial zenithal lighting in a beige room. The assessment of the 18 teeth took 15 minutes Then, a 2-hour group discussion was carried out by the GS using the same teeth and the WHO/CPI probe, questions were answered and with the help of the illustrations and teeth, an ex-vivo consensus was obtained between the GS and the examiners. A week later, an in-vivo training was carried out with 2 patients. Each examiner and the GS examined the whole-mouth patients separately in a dental chair, artificial light, a mouth mirror $\mathrm{N}^{\circ} 5, \mathrm{WHO} / \mathrm{CPI}$ probe and using a specially designed survey pro forma. Each assessment took 10 minutes per patient. Then, each patient was observed and discussed between the two examiners and the GS to obtain a clinical consensus of the indices. After reaching clinical consensus, a week later a calibration process was carried out with 8 patients. Firstly, 4 patients were examined by each participant separately in a dental chair, artificial light, a mouth mirror $\mathrm{N}^{\circ} 5, \mathrm{WHO} / \mathrm{CPI}$ probe and using a specially designed survey pro forma, then a 30-minute recess took place, followed by the examination of the last 4 patients.

Statistical Analysis: For each training process (images, models, in-vitro, in-vivo), all collected data were tabulated into Microsoft Excel v. 2013 (Microsoft, Redmond, USA), inter-rater agreement was carried out using weighted kappa, Lin's coefficient and Intraclass coefficient (Stata14/SE, StataCorp, USA).

\section{RESULTS}

An "almost perfect" global Intraclass (0.95) according to Landis and Koch (1977), a moderate Lin (1989) coefficient was obtained between the examiners (table 1).

\section{TABLE 1. Dental Aesthetic Index inter observer agreement.}

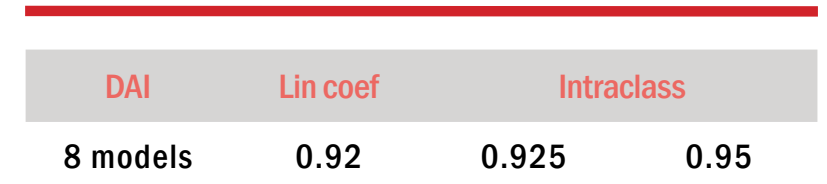


An acceptable inter agreement was observed (Table 2) with the $\mathrm{OHI}-\mathrm{S}$ and $\mathrm{CPI}$ in the final calibration process (weighted kappa index >0.55).

\section{TABLE 2. Simplified Oral Hygiene Index and Community Periodontal Index inter observer agreement.}

\begin{tabular}{lcc} 
OHI-S-CPI & OHI-S & CPI \\
\hline 2 patients & 0.55 & 0.00 \\
8 patients & 0.9510 & 0.6430
\end{tabular}

In table 3, a high inter agreement between the GS and the examiners in the final calibration process can be observed (weighted kappa index >0.80).

\section{TABLE 3. International Caries Detection and Assessment System Gold Standard-inter observer agreement.}

\begin{tabular}{ccc}
\hline ICDAS & EX1-GS & EX2-GS \\
\hline Images & 0.42 & 0.39 \\
Ex-vivo & 0.76 & 0.80 \\
2 patients & 0.71 & 0.72 \\
8 patients & 0.82 & 0.83
\end{tabular}

\section{DISCUSSION}

An acceptable in-vivo inter-agreement was obtained between the examiners, especially with ICDAS II index.

At first, undergraduate and/or post graduate students were proposed for the calibration process, but considering that after they graduate most of them are unreachable (working far away, don't have time nor interest), finally two academics were selected. As the two academics work at the Public Health Department and as these are widely accepted indices, this calibration process provided examiners with a high inter-agreement, facilitating the data collection of future epidemiological research at the Faculty of Dentistry.

The patient selection criteria of convenience sampling were preferred in order to select the most various oral health status, with or without prior orthodontic treatment, partially edentulous, good and poor oral health, etc., so the inter-agreement obtained would be suitable for a varied sample of future epidemiological studies.

For the ICDAS calibration, a GS was mandatory, as it has been established in the ICDAS Guidelines and due to the novelty of the index (Ismail et al., 2007). For the OHI-S and CPI no GS was necessary, as these indices are widely studied and used during undergraduate dental school in Chile. For the DAl index, no in-vivo calibration process was carried out, as the two examiners had a high inter-agreement in the invitro calibration process, according to Lin (1989).

In ICDAS II calibration process, as it can be noticed, inter-agreement values with ex-vivo teeth were higher than the initial 2-patient training, which suggests the importance of the in-vivo calibration, due to the differences in real conditions, such as the influence of oral humidity, examiners' visual scope, the presence of saliva, tongue, lips and breathing of the patient, among others (Mossey, 2001; Fugill, 2013). Another factor could be that during the in-vivo training, a prophylaxis and the gentle air-dry of the teeth prior to the examination was carried out, which has been demonstrated that influences in the detection of the carious lesions (Ismail et al., 2007).

The discussion groups, after the training phase were very helpful to gain consensus, as it helped to improve the inter-agreement.

\section{REFERENCES}

Cardoso CF, Drummond AF, Lages E, Pretti H, Ferreira $\mathrm{EF}$, Abreu MH. The dental aesthetic index and dental health component of the index of orthodontic treatment need as tools in epidemiological studies. Int J Environ Res Public Health. 2011; 8(8): 3277-86.

Cartes-Velásquez R, Araya E, Valdés C. Maloclusiones y su impacto psicosocial en estudiantes de un liceo intercultural. Int J Odontostomat. 2010; 4(1): 65-70.

D'Aiuto F, Gable D, Syed Z, Allen Y, Wanyonyi KL, White S, Gallagher JE. Evidence summary: The relationship between oral diseases and diabetes. Br Dental J. 2017; 222(12): 944948. 
Dietrich T, Webb I, Stenhouse L, Pattni A, Ready D, Wanyonyi KL, White S, Gallagher JE. (2017). Evidence summary: the relationship between oral and cardiovascular disease. $\mathrm{Br}$ Dental J. 2017; 222(5): 381-385.

Dimberg L, Arnrup K, Bondemark L. The impact of malocclusion on the quality of life among children and adolescents: a systematic review of quantitative studies. Eur J Orthod. 2014; 37(3): 238-247.

Fugill M. Defining the purpose of phantom head. Eur J Dent Educ. 2013; 17(1): e1-e4.

Gil-Montoya JA, de Mello AL, Barrios R, Gonzalez-Moles MA, Bravo M. Oral health in the elderly patient and its impact on general well-being: a nonsystematic review. Clin Interv Aging. 2015; 10: 461-7.

Greene JG, Vermillion JR. The simplified oral hygiene index. J Am Dent Assoc. 1964; 68(1): 7-13.

Ismail Al, Sohn W, Tellez M, Amaya A, Sen A, Hasson H, Pitts NB. The International Caries Detection and Assessment System (ICDAS): an integrated system for measuring dental caries. Community Dent Oral Epidemiol. 2007; 35(3): 170-178.

Jenny J, Cons NC, Kohout FJ, Jakobsen J. Predicting handicapping malocclusion using the Dental Aesthetic Index (DAI). Int Dent J. 1993; 43(2): 128-132.

Jenny J, Cons NC. Comparing and contrasting two orthodontic indices, the Index of Orthodontic Treatment Need and the Dental Aesthetic Index. Am J Orthod Dentofacial Orthop. 1996; 110(4): 410-416.

Landis JR, Koch GG. The measurement of observer agreement for categorical data. Biometrics. 1977; 33(1): 15974.

Lin LI. A concordance correlation coefficient to evaluate reproducibility. Biometrics. 1989; 45(1): 255-68.

Manger D, Walshaw M, Fitzgerald R, Doughty J, Wanyonyi KL, White S, Gallagher JE. Evidence summary: the relationship between oral health and pulmonary disease. $\mathrm{Br}$ Dent J. 2017;222(7), 527-533.

Mashima I, Theodorea CF, Thaweboon B, Thaweboon S, Scannapieco FA, Nakazawa F. Exploring the salivary microbiome of children stratified by the oral hygiene index. PloS One. 2017; 12(9): e0185274.

Mossey P. Scope of the OSCE in the assessment of clinical skills in dentistry. Br Dent J. 2001; 190(6): 323-6.

Onyeaso C0, Begole EA. Relationship between index of complexity, outcome and need, dental aesthetic index, peer assessment rating index, and American Board of Orthodontics objective grading system. Am J Orthod Dentofacial Orthop. 2007; 131(2): 248-52.

Petersen PE. The World Oral Health Report 2003: continuous improvement of oral health in the 21st century-the approach of the WHO Global Oral Health Programme. Community Dent Oral Epidemiol. 2003; 31: 3-24.

Pitts N. 'ICDAS'--an international system for caries detection and assessment being developed to facilitate caries epidemiology, research and appropriate clinical management.
Community Dent Health. 2004; 21(3): 193-8.

Spencer AJ, Allister JH, Brennan DS. Utility of the Dental Aesthetic Index as an orthodontic screening tool in Australia. Adelaide: University of Adelaide; 1992.

Sun L, Wong HM, McGrath CP. Relationship Between the Severity of Malocclusion and Oral Health Related Quality of Life: A Systematic Review and Meta-analysis. Oral Health Prev Dent. $2017 ; 15(6)$.

Suresan V, Das D, Jnaneswar A, Jha K, Kumar G, Subramaniam GB. Assessment of dental caries, oral hygiene status, traumatic dental injuries and provision of basic oral health care among visually impaired children of Eastern 0disha. J Indian Soc Pedod Prev Dent. 2017; 35(4), 284-290.

Taibah SM, Al-Hummayani FM. Effect of malocclusion on the self-esteem of adolescents. J Orthodont Sci. 2017; 6(4), 123.

WHO. Oral health surveys: basic methods. Geneva: World Health Organization; 1997.

World Health Organization. Oral health surveys: basic methods. Geneva: World Health Organization; 2013. 